\title{
A construção do cuidado pela equipe de saúde e o cuidador em um programa de atenção domiciliar ao acamado em Porto Alegre (RS, Brasil)
}

\author{
The construction of care by the health team and the caretaker \\ within a home-care program for bedridden patients \\ in Porto Alegre (RS, Brazil)
}

Ivani Bueno de Almeida Freitas ${ }^{1}$

Stela N azareth M eneghel ${ }^{2}$

LucildaSelli (in memoriam)

${ }^{1}$ Universidade do Vale do Rio dos Sinos. Av. Unisinos 950, Bairro Cristo Rei. 93022-000 São Leopoldo RS. ivanifreitas@terra.com.br 2 Curso de Análise de Políticas e Sistemas de Saúde, Escola de Enfermagem, U niversidade Federal do Rio Grandedo Sul.
Abstract The main objective of this case study was to understand the construction of care in the Homecare Program for Bedridden Patients (PADA) of a basic health unit (UBS) in Porto Alegre, RS. Data were obtained from 13 caretaker groups in the UBS, and participating observation recorded in field diary in the patient's homes. An analysis of the discourse practices was performed inspired in Foucault's discourse concepts speeches and in studies on ethics and self-care. In thegroups, the caretaker occupied a space that we metaphorically called the Delphic Oracle, a place for acceptance, listening and support. Hearing the dialogues that took place between the team and the caretakers made us face the contradiction present in the institutional discourse, which both stimulates self-care, and imposes rules, duties, tasks. Care as a citizenship right opposite to care as submission and subjugation created tension inside the group several times. Foucault's notion of care comprises a synthesis of the exercise of a person over his- or herself, making him or her better as a human being and, at the same time, capacitating him or her to become a better citizen.

Key words Homecare Program, Elderly, Care
Resumo Esteartigo éum estudo de caso cujo objetivo principal foi compreender a construção do cuidado no Programa deAtendimento Domiciliar ao Acamado (PADA) de uma unidade básica de saúde(UBS) em Porto Alegre, RS. Os dados foram obtidos em 13 grupos de cuidadores na U BS e em observação participante registrada em diário de campo nos domicílios. Foi realizada análise das práticas discursivas, inspirada nos conceitos de discurso de Foucault e nos estudos sobre ética e cuidado de si. No transcurso dos grupos, os cuidadores ocuparam um espaço que chamamos metaforicamente de O ráculo de D elfos, lócus de acolhimento, escuta edesuporte. Escutar os diálogos travados entreequipeecuidadores defrontou-nos com a contradição presente no discurso institucional que ao mesmo tempo que estimula o cuidado de si impõe normas, deveres e fazeres. 0 cuidado como direito de cidadania em contraposição ao cuidado como submi ssão eassujeitamento tensionou o grupo em vários momentos. A noção foucaultiana de cuidado compreende uma síntese entre 0 exercício de uma pessoa sobre ela mesma, tornando-a meIhor como ser humano e, ao mesmo tempo, capacitando-a a se tornar melhor como cidadão. Palavras-chave Programa de atenção domiciliar, Idoso, Cuidado 
Introdução

A produção de arranjos gerenciais dos serviços de saúde no território nacional vem operacionalizando ações de acordo com a realidade local. $\mathrm{Na}$ região noroeste de Porto Alegre (RS), considerada a segunda em número de idosos, insere se uma unidade básica de saúde (UBS) que, desde 2002, a partir das necessidades expressas pela população, implantou um Programa de Atendimento Domiciliar ao Acamado (PADA) cuja equipe tem se organizado para atender às demandas específicas dos cuidadores desses usuários acamados. Um dos dispositivos encontrados foi a nucleação de um grupo que constituiu um espaço de encontro daqueles que operam com o cuidado - equipe de saúde e cuidadores familiares.

0 estudo realizado sobre o PADA e o grupo de cuidadores encontrou sua vertente em obras sobre o cuidado. Na discussão da noção de cuidado, buscou-se inspiração na obra de Foucault, principalmente nos últimos estudos dedicados à ética, sinalizando o sujeito que constitui a si próprio e as artes da existência, concebidas como ações voluntárias por meio das quais os homens não somente fixam regras de conduta mas procuram se transformar e fazer da vida uma obra ética eestética.

Foucault real izou estudos sobreo cuidado tendo como referencial a filosofia greco-romana e a espiritualidade cristã. Suas pesquisas buscaram compreender o sujeito e a verdade inseridas no domínio da ética e das análises sobre o conceito de si. Ele tratou a problemática da subjetividade buscando saber de que forma foram tramadas, no 0 cidente, as relações entre o sujeito ea verdade, procurando entender o conhecimento de si, em sua rel ação com a política ecom a pedagogia ${ }^{1}$.

A noção do cuidado de si deriva da noção grega de epimeléia heautoû ou o fato de se ocupar consigo, dese preocupar consigo. Jáo princípio délfico gnôthi seauton quer dizer conhece-tea ti mesmo e inclui três questões: (1) ocupar-se consigo mesmo; (2) o eu com quem é preciso ocupar-se; e (3) o cuidado de si. É preciso compreender, esclarece o filósofo, que o termo epimeléia não évago; ele designa todo um conjunto de ocupações, de sociabilidades e obrigações, inclusive em relação a si mesmo.

Em sua origem, o "conhece-te a ti mesmo" estava subordinado à dimensão do "ocupar-se consigo", ou seja: na Grécia, o "cuidado de si" desfrutava de privilégio e precedência com relação ao "conhecimento de si", que na sociedade ocidental vai se inverter por completo, a partir do momento cartesiano, que desqualificou o princípio do "cuidado de si". Desse modo, devido à subordinação do "cuidado desi" ao "conhecimento desi", a filosofia se desarticulará daquilo queFoucault chamou "espiritualidade" ou o conjunto de procedimentos para ter acesso à verdade. Para os gregos, não bastava apenas o ato do conhecimento para que o sujeito alcançasse a verdade; para atingi-la, era preciso realizar uma conversão do próprio sujeito, isto é, ele próprio devia se modificar para se tornar, por meio das "técnicas desi", uma outra pessoa. A cultura de si pode ser caracterizada pel o fato de quea arte da existência - a techne tou biou - encontra-se dominada e orientada pelo princípio segundo o qual é preciso ter cuidados consigo².

A relação entre o cuidado de si e o conhecimento de si se dá de modo diferenciado em três períodos: o socrático platônico, em que os dois princípios estão intimamentearticulados; o período dos séculos I e II da era cristã, em que o cuidado transforma-se em prática cotidiana; e os séculos IV e V de nossa era, em que a ascese cristã ganha força, marcada pela renúncia de si em benefício de Deus e, portanto, do abandono do cuidado de si ${ }^{3}$.

Outra noção importante articulada ao cuidado éa de governamentalidade; remetendo outra vez a Foucault, é preciso cuidar de si mesmo para ser capaz de cuidar do outro. As tecnologias de si são os meios pelos quais os sujeitos realizam certo número de operações sobre seu corpo esua alma, obtendo uma autotransformação que teria como principal objetivo al cançar o conhecimento. Além do mais, as tecnologias enunciam as estratégias com as quais se criam formas de governabilidade, o governo de si por si e suas articulações com o governo dos outros ${ }^{4}$.

0 cuidado de si é uma síntese, um ponto de conexão entre a história da subjetividadee as formas de governabilidade. Para Foucault, quando os gregos preconizavam o cuidado desi, naverdade referiam-se ao cuidado da alma como espaço para o pensamento, para a reflexão, para o diálogo e para o encontro com o outro. N este sentido, a ética é pensada como a forma privilegiada de reflexão sobre as maneiras de viver, ea vida tratada como uma obra de arte. É por este motivo que Foucault retorna aos gregos para, na realidade, pensar quem somos nós hoje: quais são nossos modos deexistência, nossas possibilidades devida ou nossos processos de subjetivaçãa $0^{5-7}$.

Ayres $^{8}$, ao interpretar a fábula-mito sobre o cuidado descrita por Higino, na perspectiva do cuidado em saúde, destaca que o cuidado de si 
constitui-se, simultaneamente, um atributo euma necessidade universal dos seres humanos.

Pinheiro e Guizardi 9,10 abordam a noção de cuidado como uma ação integral, com significados e sentidos voltados para a compreensão de saúde como direito de ser, e não apenas relativo ao nível de atenção do sistema desaúde ou como procedimento técnico. A ação integral éentendida como entrerrelações de pessoas, traduzidas em atitudes de tratamento digno erespeitoso com qualidade, acolhimento e vínculo. Schiffler e M erhy ${ }^{11}$ e outros pesquisadores ${ }^{12-14}$ acrescentam a essa ação integral a noção de responsabilização, trabalho vivo em ato, produção de formações relacionais, ou seja, redes de produção de vida. Pinheiro e Guizardi ${ }^{10}$, ao estudarem equipes do Programa de Saúde da Família, observaram que essas equipes operam como dispositivos abertos, configuradas pela imanência dos encontros que as atravessam e conformam.

Outra reflexão teórico-filosófica aborda o cuidado de forma ambivalente, sendo ele político (presente na dialética do homem) e solidário, conformando-se nas relações como emancipatório de processos de trabalho e de domínio ${ }^{15,16}$. A politicidade do cuidar se expressa por meio da mediação de interesses, da negociação árdua de projetos e pelo modo de ser solidário ou de vir a ser político.

Este artigo apresenta alguns resultados da pesquisa que teve como objetivo buscar a compreensão de como a equipe de saúde do PADA, usuários ecuidadores vivenciam o cuidado, buscando contribuir para a compreensão e o uso do dispositivo cuidado nos serviços de saúde.

\section{Trajeto metodológico}

Trata-se de um estudo de caso, um tipo de pesquisa focada em um tópico específico, mas que não é apenas uma técnica específica. É uma das principais modalidades do paradigma qualitativo, adaptada da tradição médica, eque considera a unidade social estudada como um todo. Objetiva a análise holística, completa, de informações detalhadas, através de um mergulho profundo e exaustivo numa realidade social mostrando o que está por trás da homogeneidade. Aliado a esta modalidade de estudo, a técnica de observação participante tem suas origens na pesquisa antropológica, apresentando vantagem metodológica por ser única e por permitir acompanhamento prolongado e minucioso das situações, exigindo escuta dialética dos atores sociais ${ }^{17}$.
A compreensão participativa é produzida a partir de conversas e diálogos, quando existe a possi bilidade de evidenciar mediações e contradições entre a parte eo todo, tornando esta compreensão progressiva, contínua e esclarecedora sobre os significados ${ }^{18,19}$. 0 projeto de pesquisa foi aprovado pelo Comitê de Ética em Pesquisa da Secretaria M unicipal deSaúdedePorto Alegre.

Porto Alegre conta com uma população de 1.360.000 habitantes e está dividida em oito Gerências Distritais de Saúde. 0 estudo foi realizado em uma unidade básica de saúde (UBS) inserida no território da Gerência Noroeste e fazendo parte da rede pública de saúde, com uma área adscrita de 12 quilômetros quadrados e uma população de referência de 63.690 habitantes; é considerada a segunda região em número deidosos, com 11.120 indivíduos neste grupo etário. A pesquisa estudou um programa de atenção domiciliar à pessoa acamada, o Programa de Atendimento Domiciliar ao Acamado (PADA). Os sujeitos do estudo são os operadores de cuidados do PADA constituídos pela equipe técnica da UBS e cuidadores domiciliares.

$\mathrm{Na}$ realização da pesquisa, foram utilizados dados obtidos em grupos de cuidadores realizados na U BS e observação participante registrada em diário de campo, nos domicílios cujos cuidadores participavam das atividades em grupo.

0 grupo de cuidadores foi pensado como um dispositivo, ou seja, uma ferramenta para operar transformações e mudanças entre os participantes ${ }^{20-23}$. Fernández ${ }^{24}$, em uma genealogia do campo grupal, reflete sobre a complexidade do processo grupal, já que cada grupo possui movimentos próprios, o que significa ser ímpar em suas imbricadas utopias e significações.

Foram 13 grupos que apresentaram os seguintes objetivos e temas de discussão: apresentação da equipe de saúde e cuidadores; definição do espaço grupal como local de cuidado com o cuidador; aplicação de técnicas (oficinas) como agenciadoras de problematização, reflexão crítica e auxílio na tomada de decisões. A dimensão política do cuidado foi explorada através do entendimento do cuidador e dos usuários como cidadãos possuidores de direitos.

Para realizar a análise dos dados, utilizou-se o conceito de discurso, no sentido amplo que abarca todos os tipos de interações verbais, formais einformais, inclusiveas produzidas em grupos e oficinas. Discursos podem ser interpretados por meio de textos, em um processo de explorar as conotações, alusões e implicações evocadas. São sistemas de declarações, emitidos por 
sujeitos posicionados, atravessados por contradições e historicamente localizados, que reproduzem relações de poder e possuem efeitos ideológicos, os quais, por sua vez, permitem a emergência de espaços de manobra e resistência23,25.

0 discurso é, segundo Foucault, um conjunto de saberes que desejam tornar-se poder, mas para isso énecessário que sejam materializados em uma enunciação. Os elementos que compõem a análise dediscurso são: o discurso, 0 enunciado, a enunciação, o saber, o poder, o autor e a formação discursiva. Para empreender a análise de um discurso, deve-se antes considerá-lo como um elemento constituinte de uma série; deve-se considerar e conhecer também a regularidade dos fenômenos, isto é, dos eventos que estão em curso durante a elaboração deste discurso, e os limites de probabilidade de sua emergência ${ }^{26}$. 0 discurso é o local da articulação entre saber e poder. Para Foucault, é por sua capacidade de produção que o poder é aceito, pois além de produzir saber e prazer, o poder produz discursos ${ }^{27}$. A homogeneidade e a consistência no discurso fazem parte dearranjos sociais que seguem uma lei heurística, quase uma "coação moral da pesquisa", que procura suprimir as contradições, apagar as diferenças e as polêmicas, esquecer que o discurso dos homens está constantemente minado pela contradição dos seus desejos, das influências que eles sofreram ou das condições em que vivem.

Pela análise das práticas procurou-se reconhecer as incongruências e as contradições nos discursos, quer seja no discurso institucional, enunciado pela equipe do PADA, quer seja nos discursos dos cuidadores presentes nos grupos. Analisar o discurso éfazer com que desapareçam e reapareçam as contradições; é mostrar o jogo que neleelas desempenham; émanifestar como ele pode exprimi-las, dar-Ihes corpo, ou emprestar-Ihesuma fugidia aparência ${ }^{28}$. Assim como os discursosinstitucionais, os enunciados cotidianos dos falantes ou os repertórios interpretativos apresentamse inconsistentes, fragmentados e contraditórios. Esses aspectos controversos do linguajar cotidiano foram denominados de dilemas ideológicos ${ }^{29}$, mostrando que a argumentação do dia a dia das pessoas está repleta de incongruências ${ }^{30}$.

Portanto, inspirados nos estudos de Fou cault sobreética ecuidado de si, empreendemos a análise das práticas discursivas dos operadores do cuidado no PADA (equipe técnica e cuidadores domiciliares), considerando os enunciadosna sua condição de opacidade e inquirindo-os exaustivamente, buscando encontrar as suas regularidades e as suas contradições.
Construindo o cuidado no PADA: o Oráculo deDelfos

No cotidiano das famílias atendidas pelo PADA, transcorriam dificuldades de ordem econômicosocial como desemprego, alto custo detratamento com a compra de medicamentos, fraldas, distanciamento de familiares, sobrecarga nos afazeres domésticos e no cuidado do acamado, abandono de vida social; além de sofrimentos e ansiedades oriundas da dificuldade no manejo com o acamado e com o modo de viver a vida dos atores envolvidos.

A equipe de saúde do PADA, pautada na escuta dessas dificuldades vividas pelos cuidadores de usuários acamados, propôs uma prática grupal para acolher e cuidar desses sujeitos.

As reflexões que fazemos estão fundamentadas nos dados empíricos, produzidos nos 13 encontros com cuidadores, realizados no ano de 2006, e na observação participante que ocorreu durante as visitas domiciliares.

$\checkmark$ inte e nove pessoas participaram dos grupos, sendo 24 delas cuidadores domiciliares e as demais, integrantes da equipe. Esses cuidadores domiciliares eram na maioria mulheres. Eram elas familiares dos acamados, já em idade idosa, situadas em estratos socioeconômicos de baixa renda, sobrecarregadas com a responsabilidade de cuidado do familiar acamado e em luta pela sobrevivência.

A ideia da equipeeraa deproporcionar suporte solidário e agenciamento de mudanças, possibilidade de livre expressão das emoções, dos desejos e dos afetos. No transcurso do processo grupal, os cuidadores ocuparam um espaço, que chamamos metaforicamente de Oráculo de Delfos, um lócus de acol himento, de escuta e de cuidado.

A metáfora do Oráculo de Delfos constitui o eixo central desta discussão, condutor da problematização e dispositivo de agenciamento da construção do cuidado.

$\mathrm{Na}$ Grécia antiga, D elfos era o santuário do deus da curaA Apolo, encimado pela inscrição "Conhece teati mesmo" e cenário de atenção ecuidado aos doentes ${ }^{1}$. Desde a antiguidade até a modernidade, o sujeito, para ter acesso à verdade, precisava realizar certas práticas específicas. No oráculo, eram realizados ritos de purificação necessários para que os deuses pudessem dizer verdades, incluindo-se o escutar música, o respirar perfumes e a prática do exame de consciência.

Os cuidadores iniciaram o grupo falando todos ao mesmo tempo e disseram da culpa, estresse, sobrecarga emocional e financeira, sofri- 
mento e desespero que experimentavam no dia a dia. Eles se apresentaram a partir da descrição do acamado, ou seja, substituíram a identidade própria pela de cuidador(a). M ostraram-se fundidos à pessoa que cuidavam, fato percebido na troca de nomes, quando respondiam pelo nome do familiar acamado. 0 relato das histórias de vida foi focado no sofrimento; contaram que as pessoas de quem cuidavam tinham doença de Alzheimer e não os reconhecia. Um deles disse: "não tenho prazer algum"; e outro: "é capaz de irmos antes dos acamados".

Problematizamos com eles a "escravidão" identitária em que o cuidador não tem nome, atende pelo nome da pessoa que cuida, sufocado na ausência de espaço "entre as relações" 10 .

Uma dificuldade apontada pelos cuidadores foi a de estabelecer limites para o cuidado, já que costumam tratar do acamado até a exaustão, até o corpo se manifestar por meio de depressão, fadiga e dores musculares. Expressaram o desejo de cuidar de si e trocaram receitas caseiras para aliviar a dor do corpo, as quais atravessaram as falas sobre o não cuidado de si. Entendemos que as receitas caseiras podem significar uma estratégia coletiva de resistência ou um mecanismo de acomodação, na medida em que é uma ação paliativa efácil de ser realizada.

Foucault ${ }^{4}$, ao construir a genealogia do cuidado, identificou quatro tipos detecnologias desi que não funcionam em separado, associam-se a algum tipo particular de dominação e implicam uma forma de aprendizado e de modificação dos indivíduos. São elas: tecnologias de produção, quando semanipulam etransformam coisas para efetuar sua produção; tecnologias de sistema de signos, por meio do uso dos sentidos e significados; tecnologias de poder, que consistem na subjetivação dos sujeitos para submetêlos à dominação; tecnologias de si ou transformação de si mesmo para alcançar um estado de felicidade e sabedoria. Assim, os modos de produzir a subjetivação passam por esses tipos detecnologias aplicadas ao trabalho sobre si mesmo.

Dentre as técnicas de si ou ferramentas usadas para o cuidado de si, Foucault ${ }^{1,4}$, remontando à Grécia, identifica a escuta, a dietética, o cuidado com o corpo e o exame de consciência. No processo grupal, a ferramenta da escuta foi exercitada nas duas direções: a equipe ouvindo as queixas dos cuidadores e esses ouvindo as problematizações da equipe etambém as normas. A equipe de saúde pôs em discussão o caráter árduo do cuidado, mostrando exemplos da cotidianidade dos cuidadores. Os cuidadores contra- puseram a noção dialética de cuidado, imputando-Ihe a dimensão do amor, e negando o cuidado que assujeita, embora ele tenha aparecido no aforismo quejustifica a existência como um eterno servir e trazido por eles ao grupo: "quem não vive para servir não serve para viver".

A dietética, como técnica de cuidado, foi focalizada na alimentação adequada que tem o poder de modificar o humor do acamado. Uma cuidadora disse que o doente, "quando escuta 0 liquidificador, emburra". A equipe pediu à cuidadora que pensasse sobre a apresentação da comida: "N ão seria demasiado ruim, na velhice, receber uma alimentação como aquela? A apresentação liquefeita dos alimentos não seria repugnante?" A maioria dos acamados do PADA encontra-se em estado precário de nutrição, e a equipe se preocupa com os cuidados dietéticos possíveis. Recomendou-se o esmagamento dos alimentos e oferecê-los um a um ao acamado. No caso do uso de sonda nasoentérica, extrair o caldo de frutas e oferecer em pequenas porções para que 0 acamado possa saborear. No discurso institucional sobre a dietética, não perguntamos o quanto essas prescrições significam em termos de dispêndio adicional de esforço por parte dos cuidadores, implicando não cuidar de si para cuidar do outro.

Uma das consequências da situação de acamado é a desnutrição proteico-calórica, o que leva à indicação de sonda nasoentérica. Os cuidadores já haviam vivido alguma experiência marcante com esse artefato de cuidado e relutavam em aceitar o uso da sonda devido à dificuldade de manejo, à contenção corporal que ela implica para alguns casos e pela ideia de morte que ela traz. "Qualquer coisa, menos a sonda." Um dos cuidadores recolocou a sonda na esposa acamada, o que produziu o comentário da pesquisadora: "Dando uma de enfermeiro?" O cuidador assumiu a engenhosidade com que dribla a falta de recursos e luta para manter a mulher viva, como estratégia de resistência: "É, dando uma de enfermeiro." Esse diálogo assinala uma contradição, entre o Oráculo de Delfos pensado pela equipecomo espaço decuidado e decura ea manutenção do poder de curar do técnico.

A tecnologia do examede consciência pertencea uma classe de exameinterior, em quea escuta de si fundamenta a tomada de decisões ${ }^{4}$. No grupo, o exame de consciência, aliado ao recordatório, foi umas das tecnologias empregadas pela equipe de saúde para que os cuidadores pudessem refletir sobre suas vidas, perceber os pontos críticos, elencar os elementos-chave para a to- 
mada de decisões eidentificar recursose potências disponíveis.

H ouve situações presenciadas nas visitas domiciliares em que o usuário controla toda a família, designa tarefas, turnos de trabalho, emite juízos, recusa terapêuticas. Uma mulher acamada regulava o ritmo do ambiente, fazendo os fiIhos realizarem tarefas e enunciando ordens. "Parece um general, do seu posto comanda a todos", foi o comentário da equipe. Em outro domicílio, no horário da visita, chegou a encomenda de uma cadeira de estofado sintético imponente, ondefoi acomodado o paciente. Um profissional da equipe observou: "Ele parece um rei, na cadeira", e a cuidadora familiar: "E eu, uma escrava”.

0 cuidado prestado pelos cuidadores, por vezes silenciando a escuta do corpo, mostra a eficácia dos processos de assujeitamento e disciplinarização presentes na sociedade, queincidem principalmente sobre as mulheres, as "grandes cuidadoras", cuja social ização degênero Ihes atribui a tarefa social de cuidado dos grupos vulneráveis: crianças, idosos e incapacitados ${ }^{31}$.

Os cuidadores mostram-se tensionados entre a situação de "estresse, sobrecarga, sofrimento, fal ta de tempo para si" e "o poder" - enunciado com orgulho - que consiste em cuidar do familiar e serem aqueles que sabem até o que "o olhar do acamado ou seu gemido significam". Sobre esses cuidadores recaem a responsabilidade e a confiança irrestrita do parente acamado ou da família, que muitas vezes se exime de qualquer auxílio. Estudos ${ }^{31,32}$ mostram que o familiar "escolhido" para cuidar o faz por falta de opção e que na maioria das vezes não conta com a ajuda de filhos, vizinhos e parentes.

Desta forma, o grupo se moveu entre os dile mas representados pelo cuidado como assujeitamento eimposição epelo cuidado como possibilidade de autonomia e governabilidade.

A equipe se defrontou constantemente com as contradições presentes no discurso institucional que, ao mesmo tempo que estimula os cuidadores para exercitar o cuidado desi , impõe normas, deveres, fazeres.

Em todos os momentos, as posições contraditórias, tanto da equipe quanto dos cuidadores, atravessaram as relações e as práticas. Por um lado, o cuidado foi enunciado como gerador de autonomia e de liberdade; por outro, ele se mostrou normatizador e calcado na noção de dever. Ouvindo a equipe, havia situações em que o objetivo era tentar "colocar ordem" nas falas das pessoas e organizar a liberdade de expressão dos participantes. Além disso, a cobrança por assi- duidade dos cuidadores nos encontros e o reforço à não institucionalização do familiar acamado compuseram um discurso às vezes visando à autonomia, às vezes heterônomo, moralizante e culpabilizador.

Em um "jogo de palavras", refletimos sobre alguns enunciados expressos ao longo do processo grupal. A ideia do jogo era o descarte das palavras, em uma "mala sem alça", ou a guarda no "baú da felicidade". A técnica propiciou uma acirrada discussão, e nesse tensionamento algumas palavras foram escolhidas por consenso, embora nem sempre o cuidador que escolheu a palavra concordasse com a decisão. Os cuidadores acataram a vontade coletiva, assim como 0 fazem no cotidiano, mesmo quando ela representa valores tradicionais que se sobrepõem às vontades individuais. A técnica tinha o intuito problematizador, embora os cuidadores tenham se submetido à moral convencional, descartando, por exemplo, a palavra "asilo", que representa a institucionalização do familiar - "é uma judiaria colocar alguém em um asilo" -, parecendo-nos mais por noção de dever do que por livre opção. Esta solução suprime os conflitos em troca do esquecimento de si.

Outro aspecto contraditório foi o reconhecimento da equipe de saúde, por alguns cuidadores, como presente e atuante, e também as críticas erei vindicações por um atendimento melhor e mais assíduo. Um cuidador entregou para o diretor da UBS uma carta falando sobre seu desapontamento e desagrado com a equipe que havia alterado a periodicidade de visita domiciliar a seu familiar. Essa carta suscitou al guns questionamentos por parte da equipe: Aquela carta não seria um pedido de ajuda? A equipe deveria pensar sobre o tempo que o cuidador teria para sentir-se capaz de realizar o cuidado enão somente considerar o estado do acamado para reprogramar a periodicidade de visita?

Essa capacidade de reflexão da equipe como constitutivo do processo de trabalho, a escuta, os espaços intercessores quevingam das relações, o trabalho vivo em ato enquadram o PADA como tecnologia leve e leve-dura, centrada nos conhecimentos, sabedorias, experiências, atitudes, compromissos, responsabilidades e com capacidade de encontrar linhas de fuga à normativida$\mathrm{de}^{14,33,34}$. A metáfora pensada pelas autoras - 0 Oráculo de Delfos - captura a imagem grega do espaço reflexivo, estimulador da mutação de comportamentos, do exercícios desi, assim como a fábula mito do cuidado - ambos os dispositivos a operar a construção possível do cuidado 
nos projetos de felicidade envolvendo os operadores do cuidado. 0 exercício eas técnicas utilizadas pela equipe de saúde no processo grupal buscaram problematizar o cotidiano dos cuidadores por meio do diálogo ${ }^{8}$ no desejo de potencializar o cuidado.

O Oráculo deD elfos: a politicidade do cuidado

A mudança do modelo assistencial requerido pelos trabal hadores em saúdee usuários tem alavancado transformações necessárias à construção de um novo paradigma de cuidar em saúde. Desdea implantação do Sistema Ú nico deSaúde, tem-se buscado construir estratégias que deem conta da técnica e da utopia do cuidado, considerando a dimensão da integralidade da atenção à saúde na produção de ações em defesa da vida ${ }^{9}$.

Trabalhar em saúde significa assumir uma posição de estar-aí junto ao outro para atualizar o projeto defelicidadeexistencial desseoutro. Esta visão de responsabilidade compreen de um caráter de compartilhamento e a interrogação "acerca de por que, como e quanto nos responsabilizamos em relação aos projetos de felicidade daqueles de cuja saúde cuidamos". Estas perguntas instigam o repensar das práticas de saúde num processo de dialogicidade, transcendendo o tecnicismo e buscando a flexibilização e a permeabilização dos horizontes normativos dessas práticas. Essa práxis procura explorar novas intervenções em saúde menos ortodoxas, incluindo a participação política de indivíduos e comunidades, e gerar "multiplicidades anti-hegemônicas, de compreensão do sofrimento humano na produção da cidadania"8.

A equipe de saúde escolheu para narrar ao grupo de cuidadores a fábula-mito de $\mathrm{Higino}^{35}$, como uma síntese do processo grupal, uma valoração ética eestética do ato de cuidar, epropôs queeles confeccionassem esculturas deargila simbolizando o cuidado. Ao falar sobre as peças produzidas, eles disseram do cuidado que liberta e do cuidado que oprime ${ }^{15,36:}$ "a mãe, apesar de tudo, tem o coração bom"; "tenho que ter o coração grande". Os enunciados dos cuidadores estiveram tensionados entre sentimentos antagônicos, entre o senso do dever e a busca da singularidade. A negação do próprio discurso pelas contradições é evidente, o desejo é sufocado pelo dever, a obrigação de ser grande e generoso em doações, quando, na verdade, se é cativo e finito quando não reabastecido.
A noção de governamentalidade remete ao caráter político do cuidado, ou seja, governamentalidadeéuma ação que se exercena relação com o outro, manifesta na polaridade ação/resistência. Fou cault ressignifica o conceito de governamentalidade, considerando-a o governo desi por si, na sua articulação com as relações com o outro ${ }^{5}$. Esse conceito relaciona os dois grandes eixos da concepção foucaultiana de poder: só há possi bilidade de governo onde houver possibilidade de ação, daí o conceito de governamentalidade, e onde há poder há resistência.

Pires $^{15,36}$ define a politicidade do cuidado como ajuda e poder para a construção da autonomia de sujeitos expressos no triedro: "conhecer para cuidar melhor, cuidar para confrontar e cuidar para emancipar". A politicidade do cuidado pode ser entendida como manejo reconstrutivo da relação dialética estabelecida entre ajuda e poder para a construção da autonomia de sujeitos pensados como cidadãos, donos de suas vidas e de suas histórias. 0 cuidado é entendido em sua concepção ampla, apresentando potencial disruptivo e inovador, capaz tanto de tutelar quanto de emancipar pessoas. Fala-se em politicidade do cuidado para caracterizar o movimento de integração, confronto e ruptura presente nas dinâmicas vivas que se estabelecem entre os homens, ou seja, significa entender o cuidar no âmbito da centralidade do político que o define, em que a mesma proteção pode se constituir tanto em mecanismo de dominação quanto em instrumento da autonomia dos sujeitos ${ }^{36}$.

o cuidado como direito de cidadania, em contraposição ao cuidado como submissão e assujeitamento, polarizou o grupo em vários momentos. A equipe de saúde relatou aos cuidadores o processo deterritorialização que ocorreu na UBS, resgatando a história do PADA e a importância das políticas públicas. Esse tema abriu espaço para o questionamento dos usuários sobre a atuação do PADA, e a equipe remeteu a reivindicação a fóruns de discussão e articulação, como o Conselho Local de Saúde. A reivindicação do grupo exprime a apropriação pelos seus membros das noções de direito e do caráter político do cuidado, porém a equipe desmobilizou a reivindicação e defendeu os interesses da instituição.

A construção da democracia pela informação como direito da sociedade e "não como um produto de uso privado das instituições" propicia a autonomia dos sujeitos, possibilita a prestação de serviço à sociedade e capacidade de atualização e aperfeiçoamento dos profissionais de 
saúde quando incorporam a importância da informação como prática ${ }^{37}$.

Ayres $^{8}$ traz à tona a crise de legitimidade enfrentada quando da aplicação de tecnologias e remeteà decisão sobre o que podee deveser feito aos usuários. 0 autor propõe que no encontro terapêutico humanizado seja possível criar espaços de diálogo em que o poder ouvir e fazer-se ouvir, pólos indissociáveis de qualquer legítimo diálogo, sejam elementos que fazem efetivamente surgir na cena do cuidado não um sujeito (profissional da saúde) e seu objeto (usuário ou comunidade), mas dois sujeitos eum objeto mediador.

A equipe de saúde instigou os cuidadores a se ocuparem consigo mesmos, à desconstrução/reconstrução desi mesmos, como no uso da técnica da argila, após a narrativa da fábula de Higino. Os cuidadores se esforçaram para romper com o cuidado que oprime, utilizando estratégias como a imposição de limites e a reflexão. "Estou precisando muito de um tempo para mim", disse um cuidador, querendo ser seu próprio médico, identificar seus males e propor a cura. A equipe, por sua vez, ofereceu "o espaço do grupo - o Oráculo de Delfos - como uma forma de organizar estratégias para o cuidado conjunto". No período deum ano de realização do grupo de cuidadores, foi possível dar início à construção coletiva de técnicas para o cuidado de si.

\section{Palavrasfinais}

Um dos aspectos que compreendemos melhor nesse trajeto de pesquisa foi o quanto os discursos enunciados, tanto pela equipe de saúde quanto pel os cuidadores, estão cal cados em noções de norma e de dever. Embora a equipe do PADA se mostreempenhada em cuidar da população acamada sob sua adscrição, o discurso por ela enunciado ainda é o discurso pautado no biopoder, encarregado denormalização e disci plinarização das classes subalternas. Por sua vez, há na equipe ecuidadores um desejo de ruptura ede construir o cuidado pautado em relações mais horizontais eparticipativas.

Concordamos com Pires quando diz que a politicidade do cuidado, concebida na ambiguidade que a conforma, pode desconstruir as assimetrias de poder, a partir do triedro: conhecer para cuidar melhor, cuidar para confrontar e cuidar para emancipar. A tensão entreo cuidado queassujeita/normaliza/subjuga e o cuidado que liberta esteve presente nos discursos e nas ações da equipe e cuidadores ${ }^{15,16}$.

Ao término da pesquisa, construímos uma noção de cuidado expresso como síntese entre o exercício de uma pessoa sobre ela mesma, tornando-a melhor como ser humano e, ao mesmo tempo, capacitando-a a se tornar melhor como cidadão. A ideia de governamentalidade ou de cuidar para emancipar é aquilo que vai tornar 0 sujeito solidário com os fins sociais, propostos pela sociedade democrática ${ }^{37}$.

A metáfora da construção do cuidado no PADA como 0 Oráculo de Delfos reproduz as palavras da poesia de Tom Jobim ${ }^{38}$ : É promessa de vida no teu coração / É um espinho na mão, é um corte no pé / São as águas de março fechando o verão...

$\mathrm{N}$ a vida sempre acontecerão turbulências, conflitos e contradições nas entrerrelações humanas, mas trabalhar o cuidado sem negar a presença do conflito significa entender a politicidade subversiva e transgressora do ato de cuidar. 


\section{Colaboradores}

IBA Freitas elaborou o projeto de pesquisa, coletou dados, participou da análise e redação do artigo; S M eneghel elaborou o projeto de pesquisa, participou da análise e redação do artigo; L Selli participou como coorientadora do projeto de pesquisa.

\section{Referências}

1. Foucault M. A hermenêutica do sujeito. São Paulo: Martins Fontes; 2004.

2. Foucault M . O cuidado de si: a história da sexualidade III. Rio de Janeiro: Graal; 1985.

3. Gallo S. Cuidar de si e cuidar do outro: implicações éticas para a educação dos últimos escritos de Foucault. In: Gondra J, Kohan W, organizadores. Foucault: 80 anos. Belo Horizonte: Autêntica; 2006. p. 177-190.

4. Foucault M. Tecnologías del yo y otros textos afines. Barcelona: Paidós; 1996.

5. Paniago MLF. Práticas discursivas de subjetivação em contexto escolar, 2006. [site na Internet]. [acessado 2007 maio 16]. Disponível em: http://www. oestrangeiro.net/00/lourdes.doc

6. Rateke D. A negação da violência como prática de liberdade: o cuidado de si como estratégia e princípio de uma formação ética. [site da Internet] [acessado 2007 maio 16]. Disponível em: http://www. anped.org.br/reunioes/28/textos/gt06/gt061352int.rtf

7. Vieira PP. Foucault: a cultura de si e a problematização dos nossos modos de constituição da existência. [site da Internet] [acessado 2007 maio 16]. Disponível em: http://www.anpuh.uepg.br/xxiii-simposio/ anais/textos/PRISCILA\%20PIAZEN TIN I \%20 VIEIRA.pdf

8. Ayres JRCM. Cuidado e humanização das práticas de saúde. In: Deslandes SF, organizadora. Humanização dos cuidados em saúde: conceitos, dilemas e práticas. Rio de Janeiro: Editora Fiocruz; 2006. p. 49-83.

9. Pinheiro R, Guizardi RL. Cuidado e integralidade: por uma genealogia de saberes e práticas no cotidiano. In: Pinheiro R, M atos R, organizadores. Cuidado: as fronteiras da integralidade. Rio de Janeiro: Hucitec; 2004. p. 21-36.

10. Pinheiro R, Guizardi RL. Quando a dádiva se transforma em saúde: algumas questões sobre a integralidade e o cuidado nas relações entre sociedade e Estado. In: Pinheiro R, M atos R, organizadores. Cuidado: as fronteiras da integralidade. Rio de Janeiro: Hucitec; 2004. p. 37-56.

11. Schiffler ACR, M erhy EE. Quando a atenção domiciliar vaza do (no) modelo tecnoassistencial de saúde: 0 caso de Sobral, CE, 2006. [site da Internet]. [acessado 2007 maio 16]. Disponível em: www.hucff.ufrj.br/micropolitica

12. M erhy EE, Franco TB. Por uma composição técnica do trabalho centrada no campo relacional e nas tecnologias leves. [site da Internet] [acessado 2007 maio 16]. Disponível em: www.hucff.ufrj.br/micropolitica

13. M erhy EE, Feuerwerker LM. Atenção domiciliar: medicalização e substitutividade. [site da Internet] [acessado 2007 maio 16]. Disponível em: www.hucff. ufrj.br/micropolitica

14. Franco TB. As redes na micropolítica do processo de trabalho em saúde, 2006. [site da Internet] [acessado 2007 maio 16]. Disponível em: www.hucff. ufrj.br/micropolitica

15. Pires RGM . Politicidade do cuidado e processo de trabalho em saúde: conhecer para cuidar melhor, cuidar para confrontar, cuidar para emancipar. Cien Saude Colet 2005; 10(4):1025-1035. 
16. Pires RGM . Politicidade do cuidado e avaliação em saúde: instrumentalizando o resgate da autonomia de sujeitos no âmbito de programas e políticas de saúde. Rev Bras Saúde M ater Infant 2005; (Supl.1):571-581.

17. Goldenberg M. A arte de pesquisar: como fazer pesquisa qualitativa em ciências sociais. Rio de Janeiro: Record; 2003. p. 33-35.

18. Denzin NK, Lincoln YS. O planejamento da pesquisa qualitativa: teorias e abordagens. Porto Alegre: Artmed; 2006.

19. Yun RK. Estudo de caso: planejamento e métodos. Porto Alegre: Bookman; 2002.

20. Benevides de Barros RD. Grupos e produção. In: Baremblitt G, organizador. Saúdeloucura: grupos e coletivos. v. 4. São Paulo: Hucitec; 1994.

21. Benevides de Barros RD. Grupo: a formação de um simulacro [tese]. São Paulo: Pontifícia Universidade Católica de São Paulo; 1994.

22. Benevides de Barros RD. Dispositivos em ação: 0 grupo. In: Baremblitt G, organizador. Saúdeloucura: subjetividade: questões contemporâneas. v. 6. São Paulo: Hucitec; 1997. p. 183-191.

23. M eneghel SN, Iñiguez L. Contadores de histórias: práticas discursivas e gênero. Cad Saude Publica 2007; 23(8):1815-1824.

24. Fernández AM . O campo grupal: notas para uma genealogia grupal. São Paulo: M artins Fontes; 2006.

25. 25. Parker I. Discourse dynamics: critical analysis for social and individual psychology. London: Rutledge; 1992.

26. Foucault M. A ordem do discurso. São Paulo: LoyoIa; 2000

27. Foucault M. Microfísica do poder. Rio de Janeiro: Graal; 1993.

28. Foucault M. A arqueologia do saber. Rio de Janeiro: Forense U niversitária; 2005.

29. Billig M. Ideological dilemmas: a social psychology of everyday thinking. London: Sage; 1988.
30. Edley N. Analising masculinity: interpretative repertoires, ideological dilemmas and subject positions. In: Wheterell M, Taylor S, Yates S, editors. Discourse as data: a guide for analysis. London: Sage; 2001. p. 189-228.

31. Karsch UM. Dependent seniors: families and caregivers. Cad Saude Publica 2003; 19(3):861-866.

32. Giacomin KJ, U choa E, Lima-Costa M FF. Projeto Bambuí: a experiência do cuidado domiciliário por esposas de idosos dependentes. Cad Saude Publica 2005; 21(5):1509-1518.

33. Floriani C, Schramm F. Cuidador do idoso com câncer avançado: um ator vulnerado. Cad Saude Publica 2006; 22(3):527-534.

34. Merhy EE. Em busca do tempo perdido: a micropolítica do trabalho vivo em saúde. In: M erhy $E E$, organizador. Praxis en salud: un desafío para lo público. São Paulo: Hucitec; 1997. p. 71-111.

35. Boff L. Saber cuidar: ética do humano: compaixão pela terra. Petrópolis: Vozes; 1999.

36. Ayres JRCM. Cuidado e reconstrução das práticas de saúde. In: M inayo MC, Coimbra Jr CEA, organizadores. Críticas e atuantes: Ciências Sociais e Humanas em Saúde na América Latina. Rio de Janeiro: Editora Fiocruz; 2005. p. 91-108.

37. Njaine K, Souza E, M inayo MC, Assis S. A produção da (des)informação sobre violência: análise de uma prática discriminatória. Cad Saude Publica 1997; 13(3):405-414.

38. Jobim T. Águas de março. [site da Internet] [acessado 2007 maio 26]. Disponível em: http://vagalume. uol.com.br/tom-jobim/aguas-de-março.html

Artigo apresentado em 04/12/2007

Aprovado em 14/04/2008

Versão final apresentada em 06/08/2008 